\title{
Etnobotanik Amaçlı Kullanılan Origanum acutidens Bitkisinin Toplam Fenolik- Flovonoid İçeriği, Fenolik Bileşikleri ve Element Analizi
}

\author{
${ }^{1}$ Mehmet Fidan, *2̇̇brahim Teğin, ${ }^{3}$ Mehmet Emre Erez, ${ }^{4}$ Süleyman Mesut Pınar, ${ }^{5}$ Hüseyin Eroğlu \\ ${ }^{1}$ Siirt Üniversitesi Fen Edebiyat Fakültesi Biyoloji Bölümü, 56100, Kezer-Siirt, Türkiye, mfidan7384@hotmail.com, \\ 2* Siirt Üniversitesi Fen Edebiyat Fakültesi Kimya Bölümü, 56100, Kezer-Siirt, Türkiye, İbrahim.tegin@gmail.com, \\ ${ }^{3}$ Van Yüzüncü Y1l Üniversitesi, Fen Fakültesi Moleküler Biyoloji Bölümü, 65080, Tuşba-Van, Türkiye, \\ emreerez@hotmail.com, \\ ${ }^{4}$ Van Yüzüncü Yıl Üniversitesi, Van Sağlık Yüksekokulu, 65080, Tuşba-Van, Türkiye, mesutpinar@ hotmail.com, \\ ${ }^{5}$ Van Yüzüncü Yıl Üniversitesi, Fen Fakültesi Biyoloji Bölümü, 65080, Tuşba-Van, Türkiye, \\ huseyineroglu_41@hotmail.com,
}

$\ddot{\mathbf{O z}}$

Bu çalışmada, Türkiye için endemik bir bitki olan Origanum acutidens (Hand.-Mazz.) Ietsw. iki farklı çözücü (Su ve \% 80 etanol) ile ekstrakte edildi. O. acutidens örnekleri Bingöl-Topalan'dan toplandı. (Toplayıcı kayıt numarası: MMH 1157). O. acutidens'in etanol ve su ekstraktlarının antioksidan aktiviteleri, toplam fenolik flavonoid içeriklerinin yanı sıra element ve fenolik bileşik analizleri yapıldı. Tüm analiz sonuçları $1 \mathrm{mg} / \mathrm{mL}$ ekstrakt konsantrasyonuna göre hesaplandı. Analiz sonuçlarına göre DPPH aktivitesinde; su ekstraktının \% 77,53'ü etanol ekstraktının ise \% 90,69'u inhibisyon, FRAP aktivitesinde su için $0,34 \mathrm{mg} / \mathrm{mL}$ ve etanol için $0,96 \mathrm{mg} / \mathrm{mL} \mathrm{FeSO}_{4}$ eşdeğerinde aktivite gösterdiği tespit edildi. Toplam fenolik madde tayininde su ekstraktının $86,48 \mathrm{mg} / \mathrm{mL}$ etanol ekstraktının ise $142,78 \mathrm{mg} / \mathrm{mL}$ gallik asit eşdeğeri total fenolik madde bulundu. Total flavonoid madde analizinde ise su ekstraktı için $280,58 \mathrm{mg} / \mathrm{mL}$ etanol ekstraktı için ise 503,82 $\mathrm{mg} / \mathrm{mL}$ rutin eşdeğeri flavonoid madde içeriği tespit edildi. Ayrıca $O$. acutidens bitkisinde 15 farklı fenolik bileşik ve 32 farklı element tespit edildi.

Anahtar Kelimeler: Antioksidan aktivite, element analizi, endemik, fenolik bileşik, Origanum acutidens.

\section{Total Phenolic-Flovonoid Content, Phenolic Compounds and Elemental Analysis of the Origanum acutidens Plant Used for Ethnobotanical Purpose}

\author{
${ }^{1}$ Mehmet Fidan, *2̇̈brahim Teğin, ${ }^{3}$ Mehmet Emre Erez, ${ }^{4}$ Süleyman Mesut Pınar, ${ }^{5}$ Hüseyin Eroğlu \\ ${ }^{1}$ Siirt University Faculty of Science and Art Department of Biology, 56100, Kezer-Siirt, Turkey, \\ mfidan7384@hotmail.com \\ ${ }^{2 *}$ Siirt University Faculty of Science and Art Department of Chemistry, 56100, Kezer-Siirt, Turkey, \\ ibrahim.tegin@gmail.com \\ ${ }^{3}$ Van Yüzüncü Yıl University Faculty of Science Department of Molecular Biology, 65080, Tuşba-Van, Turkey, \\ emreerez@hotmail.com \\ ${ }^{4}$ Van Yüzüncü Y1l University, Van School of Health, 65080, Tuşba-Van, Turkey, \\ mesutpinar@hotmail.com \\ ${ }^{5}$ Van Yüzüncü Y1l University Faculty of Science Department of Biology, 65080, Tuşba-Van, Turkey, \\ huseyineroglu_41@hotmail.com
}

\begin{abstract}
In this study, Origanum acutidens (Hand.-Mazz.) Ietsw. (zemul), an endemic plant for Turkey, were extracted with two different solvents (Water and $80 \%$ ethanol). O. acutidens samples were collected from Bingöl-Topalan (Collector registration number: MMH 1157). In this study, antioxidant activities, total phenolic and flavonoid content, also identification of element and phenolic compounds of $O$. acutidens (ethanol and water extracts) were analyzed. All analysis results were calculated at concentration of $1 \mathrm{mg} / \mathrm{ml}$ extract. According to these results, for DPPH activity; It was found that the water extract showed activity of 77.53\%
\end{abstract}


and ethanol extract $90.69 \%$ inhibition, at FRAP activity $0.34 \mathrm{mg} / \mathrm{mL}$ for water and $0.96 \mathrm{mg} / \mathrm{mL} \mathrm{FeSO}_{4}$ equivalent for ethanol extracts. Total phenolic content was calculated as $86.48 \mathrm{mg} / \mathrm{mL}$ in water extract and $142.78 \mathrm{mg} / \mathrm{mL}$ gallic acid equivalent total phenolic substance in ethanol extract. Total flavonoid analysis revealed $280.58 \mathrm{mg} / \mathrm{mL}$ for water extract and $503.82 \mathrm{mg} / \mathrm{mL}$ routine equivalent flavonoid content for ethanol extract. In addition, 15 different phenolic compounds and 32 different elements were detected in $O$. acutidens.

Keywords: Antioxidant activity, elemental analysis, endemic, phenolic compound, Origanum acutidens

\section{GíRiş}

Lamiaceae familyasından bir cins olan Origanum ilk olarak Linnaeus tarafindan Genera Plantarum'un 5. baskısında, Tournefort'a atıfta bulunularak tarif edilmiştir [1]. Daha sonraki süreçlerde bu cinsle ilgili çok sayıda çalışma yapılmıştır. Origanum cinsinin dünyada 43 tür ve 18 hibriti bulunmaktadır [2;3]. Türkiye Florası'nda toplam 30 taksonu tespit edilmiştir [4]. Cinse ait türlerin yaklaşık \%75'i Doğu Akdeniz alt bölgesinde yayılış göstermektedir [5-7]. Ülkemizde kekik adıyla da bilinen, Orignaum cinsine ait taksonların çoğu, halk hekimliğinde yaygın olarak baş ağrısı, baş dönmesi, öksürük, grip, gastrointestinal hastalık, bronşit, yüksek kolesterol, diyabet, karın ağrısı hipertansiyon ve diş ağrısı gibi hastalıkların tedavisinde kullanılmaktadır [8]. Origanum türleri üzerine yapılan çalışmalar antimikrobiyal, antikanser, antidiyabetik, antioksidan, antibakteriyel, antifungal, antinosiseptif ve antilipaz gibi biyolojik aktiviteler göstermiştir [9-17]. Bu çalışmalarla beraber gida veya ilaç olarak tüketilen bitkilerin içerdiği elementlerin analiz edilmesi de son derece önem arz etmektedir. Bunlarla ilgili yaygın çalışmalar olmasa da belli bazı analizlerin yapıldığı bazı çalışmalar da bulunmaktadır.

Suda yüksek oranda çözünebilme özelliğinde olan kadmiyum biyolojik fonksiyonlar açısından gerekli bir element değildir ve diğer ağır metallere göre 2-20 kat daha fazla toksik etkiye sahiptir. Bitki bünyesinde 1,0 ppm' den fazla kadmiyumun bulunması toksik etki yapmaktadır. Ayrıca $6,15 \mu \mathrm{g} / \mathrm{g}$ düzeyinde kadmiyumun birikmesi insan sağlığını olumsuz etkilediği belirlenmiştir [22,23].

Kurşunun vücuttaki absorpsiyon oran $1 \% 5$ 'tir ve bu kalsiyum ve demir minerallerin vücut tarafindan emilimini sinırlandırmaktadır. Yüksek miktarlarda kalsiyum alındığında kemik dokusuna yerleșip bağlanmıș olan kurşun kalsiyumla yer değiştirebilmektedir. Böylece sistemde serbest kalan kurşun nefrotoksisite, nörotoksisite ve hipertansiyona neden olabilmektedir [24,25]. Doğal ürünler içerdikleri biyoaktif bileşikler nedeniyle antik çağlardan beri büyük ilgi görmüşler ve ilaç keşfi ve geliştirilmesi sürecinde önemli rol oynamışlardır [26-29].

Origanum türleri genellikle yemeklerde baharat olarak kullanılır. Bununla beraber kabızlık, gastrointestinal hastalıklar, diüretik, yatıştırıcı ve antiseptik tedavisinde kullanılmaktadır [30]. Halk tarafından farklı amaçlarla kullanılan Origanum cinsi ile ilgili birçok biyolojik çalışma bulunmaktadır [31-40].
Çalışma materyalimizi oluşturan Origanum acutidens endemik ve genellikle Doğu Anadolu'da doğal olarak yayılış gösteren çok yıllık tıbbi aromatik bir bitkidir. Bu çalışma kapsamında $O$. acutides'in toprak üstü kısımlarından iki farklı çözücü ile hazırlanan ekstraklarının antioksidan aktiviteleri, toplam fenolik ve toplam flavonoid içerikleri ile element ve fenolik bileşik analizleri gerçekleştirilmiştir.

\section{MALZEME VE YÖNTEM}

\subsection{Bitki Ekstraktlarının Hazırlanması}

$\mathrm{Bu}$ çalışmada, Bingöl ili Topalan civarından toplanan $O$. acutidens örnekleri kullanılmıştır (Toplayıcı kayıt numarası: MMH 1157). Toplanan örnekler teşhis edildikten sonra herbaryum tekniklerine uygun bir şekilde preslenip herbaryum materyali haline getirilmiş ve bir örneği Siirt Üniversitesi Herbaryumunda muhafaza altına alınmıştır. Toplanan diğer bitki örnekleri gölgede kurutulmuş daha sonra blender ile öğütülerek toz haline getirilmiş ve cam kavanozlarda oda sıcaklığında muhafaza edilmiştir.

4 gr toz haline getirilmiş bitki örneği $40 \mathrm{~mL}$ çözücü $(\% 80$ etanol ve saf su) içerisinde 24 saat boyunca oda sicaklığında çalkalayıcıda çalkalandıktan sonra filtre kâğıdından süzülmüş ve ardından çözücü evaporatör ile uzaklaştırılmıştır. Suyu evaporatörde uzaklaştırmak için 70$80{ }^{0} \mathrm{C}^{\prime}$ lik, alkolün uzaklaştırılması için ise $50-60{ }^{0} \mathrm{C}^{\prime}$ lik sıcaklık ayarlanmıștır. Son konsantrasyon $10 \mathrm{mg} / \mathrm{mL}$ olacak şekilde stok çözeltiler hazırlanarak $+4{ }^{0} \mathrm{C}$ 'de çalışmalar gerçekleştirilene kadar muhafaza edilmiştir.

\subsection{Antioksidan Aktivite Tayini}

\subsubsection{DPPH Serbest Radikal Giderme Aktivitesi}

Hazırlanan her bir konsantrasyon için ayrı tüplere 1'er mL bitki ekstraktları konularak üzerine $4 \mathrm{~mL}$ DPPH $(0,001 \mathrm{M}$ DPPH, saf metanolde çözünmüş) çözeltisi eklendi daha sonra iyice karıştırılıp 30 dakika inkübe ettikten sonra Spektrofotometre ile 517 nm'de absorbansları ölçüldü. Kontrol için 4 mL DPPH üzerine $1 \mathrm{~mL}$ çözgen konuldu.

DPPH aktivitesi (\% inhibisyon $)=\left(\frac{A_{K}-A_{1}}{A_{K}}\right) \times 100$

(AK: Kontrol Absorbansı, A1: Numune Absorbans1) [41].

\subsubsection{FRAP Analizi}

Antioksidan aktivite tayini için Müller ve arkadaşlarının yaptığı protokol modifiye ederek FRAP yöntemi uygulandı 
[42]. Buna göre taze hazırlanan FRAP çözeltisi için; Sodyum asetat $(300 \mathrm{mM}, \mathrm{pH} 3,6), 40 \mathrm{mM} \mathrm{HCl}$ ile hazırlanmış $10 \mathrm{mM}$ TPTZ (2,4,6- Tris (2-pyridyl)-s- triazin) ve $20 \mathrm{mM}$ demir (III) klorür çözeltisi, 10:1:1 oranında karıştırıldı. Örnekten $100 \mu \mathrm{L}$ alınıp 3 mL FRAP solisyonu eklenerek birer dakika aralıklarla karıştırılarak $37{ }^{\circ} \mathrm{C}^{\prime}$ de 4 dakika inkübasyona birakıld1. Süre sonunda $593 \mathrm{~nm}$ dalga boyunda absorbansları alındı. Standart olarak $\mathrm{FeSO}_{4}$ kullanıldı.

\subsection{Total Fenolik Madde İçeriği}

Bitki ekstresindeki toplam çözünebilen fenolik madde miktarı Galik asit eşdeğeri olarak Folin-Ciocalteau yöntemine göre belirlendi [43]. Bitki örneğinin metanol ekstraktından $1 \mathrm{~mL}$ alınarak üzerine $1 \mathrm{~mL}$ FCR reaktifi ilave edildi. 3 dk'lık inkübasyondan sonra doygun $\mathrm{Na}_{2} \mathrm{CO}_{3}(\% 7)$ çözeltisinden $1 \mathrm{~mL}$ eklenerek, karışım oda sıcaklığında karanlıkta $90 \mathrm{dk}$ süreyle inkübe edildi. $\mathrm{Bu}$ süre sonunda spektrofotometrede 760 nm'de absorbansları ölçüldü. Aynı işlemler kontrol numunelerine ve gallik asit standart $(0,05-1$ $\mathrm{mg} / \mathrm{mL}$ ) çözeltilerine uygulanarak kalibrasyon eğrisi çizildi.

\subsection{Toplam Flavonoid Madde İçeriği}

$1 \mathrm{~mL}$ ekstrakt üzerine $400 \mu \mathrm{L} \% 80$ metanol eklendi. Daha sonra $30 \mu \mathrm{L} \% 5 \mathrm{NaNO}_{2}$ ilave edilip 6 dakika bekletildi. Süre sonunda $30 \mu \mathrm{L} \% 10 \mathrm{AlCl}_{3} \cdot 6 \mathrm{H}_{2} \mathrm{O}$ eklenip iyice çalkalanarak, 6 dakika daha bekletildi. Son olarak $400 \mu \mathrm{L} \mathrm{NaOH}$ (1M) eklendi ve 15 dakika inkübasyondan sonra $510 \mathrm{~nm}$ dalga boyunda absorbans değerleri alınmıştır.

Kör: \% 80 metanol $+30 \mu \mathrm{L} \% 5 \quad \mathrm{NaNO}_{2}+30 \mu \mathrm{L} \% 10$ $\mathrm{AlCl}_{3} \cdot 6 \mathrm{H}_{2} \mathrm{O}+400 \mu \mathrm{L} \mathrm{NaOH}(1 \mathrm{M})$

Regresyon; rutin'in farklı konsantrasyonlarına (0,1-1 $\mathrm{mg} / \mathrm{mL}$ ) göre yapıldı [44].

\subsection{Element Analizi}

0,5 g bitki materyali mikrodalga çözündürme metoduyla $\mathrm{HNO}_{3}(10 \mathrm{~mL})$ ve $\mathrm{H}_{2} \mathrm{O}_{2}(2,5 \mathrm{~mL})$ varlı̆̆ında Tablo.1.'de verilen mikrodalga ısıtma programıyla çözündürülmüştür. Oda sıcaklığına soğutulan örnekler, süzgeç kâğıdıyla süzülüp $25 \mathrm{~mL}$ 'lik falkon tüplerine aktarıldıktan sonra son hacim saf su ile belirli bir hacme tamamlanmıştır.

Tablo 1. Mikrodalga cihazının çalışma koşulları

\begin{tabular}{lcccc}
\hline & 1 & 2 & 3 & 4 \\
\hline $\mathrm{T}\left({ }^{\circ} \mathrm{C}\right)$ & 100 & 160 & 180 & 100 \\
$\mathrm{Ta}(\mathrm{dk})^{\mathrm{a}}$ & 10 & 10 & 10 & 10 \\
$\mathrm{t}(\mathrm{dk}){ }^{\mathrm{b}}$ & 5 & 3 & 3 & 3 \\
\hline
\end{tabular}

a'istenilen sıcaklıkta bekleme süresi

bIki ardışık sıcaklık arasındaki zaman

Element analizi için Thermo Scientific brand I CAP Q model ICP-MS cihazı kulanılmıştır. ICP-MS cihazının çalışma koşulları Tablo 2'de verilmiştir [45-47].
Tablo 2. ICP-MS cihazının çalışma koşulları

\begin{tabular}{|c|c|c|}
\hline Lensler & Parametreler & Değer \\
\hline $\begin{array}{l}\text { Ayırma (extraction) } \\
\text { Lens } 2\end{array}$ & Plazma gücü & 1550 \\
\hline CCT Focus Lens & $\begin{array}{l}\text { Yardımcı (Auxilary) gaz } \\
\text { akış hızı }\left(\mathrm{L} \cdot \mathrm{dk}^{-1}\right)\end{array}$ & 0,8 \\
\hline CCT Bias & $\begin{array}{l}\text { Soğutucu (Cool) gaz akış } \\
\text { hızı }\left(\mathrm{L} \cdot \mathrm{dk}^{-1}\right)\end{array}$ & 14 \\
\hline CCT Exit (çıkış) Lens & $\begin{array}{l}\text { Torch yatay (horizontal) } \\
\text { pozisyon }\end{array}$ & 0,04 \\
\hline Focus Lens & $\begin{array}{l}\text { Torch dikey (vertical) } \\
\text { pozisyon }\end{array}$ & 2,00 \\
\hline D1 Lens & & \\
\hline D2 Lens & & \\
\hline Quad Entry Lens & & \\
\hline Pole Bias & & \\
\hline
\end{tabular}

\subsection{LC-MS/MS İle Fenolik Bileşiklerin Analizi}

O. acutidens'in fenolik bileşenlerinin kalitatif ve kantitatif tayinleri Dicle Üniversitesi Bilim ve Teknoloji Uygulama ve Araştırma Merkezinde bulunan Shimadzu Neexera model UHPLC cihaz ve Shimadzu LCMS 8040 model triple quadruple kütle spektrometresi ile yapılmıştır. Kullanılan siv1 kromatografi sistemi LC-30 AD model gradient pompa, DGU-20A3R model degazer, CTO-10ASvp model kolon firını ve SIL-30AC model oto örnekleyiciden oluşmaktadır. Kromatografik ayrım, Inertsil ODS-4 model C18 (100 mm×2,1 mm, $2 \mu \mathrm{m})$ kolonda gerçekleştirilmiştir. Analiz sırasında kolon fırını $35^{\circ} \mathrm{C}$ 'ye ayarlanmıştır. Elüsyon gradiyentinde hareketli faz A için ultra saf su ve hareketli faz B için asetonitril kullanılmıştır. Ayrıca, daha iyi bir kromatografik ayrım ve iyonlaştırmayı kolaylaştırmak için su fazına $10 \mathrm{mM}$ amonyum format ve \% 0,1 formik asit eklenmiştir. Analitlerin optimum ayrımının gerçekleşmesi için yapılan pek çok denemenin ardından en uygun UHPLC gradiyent profili 5-20\% B (0-10 dk), 20\% B (10-22 dk), 20$50 \%$ B (22-36 dk), 95\% B (36-40), 5\% B (40-50 dk) şeklinde optimize edilmiştir. Hareketli faz akış hızı $0,25 \mathrm{~mL} / \mathrm{dk}$ ve enjeksiyon hacmi $4 \mu \mathrm{L}$ olarak belirlenmiştir [48]. Fitokimyasal standartın LC-MS/MS kromatogramı şekil 1 'de verilmiştir.

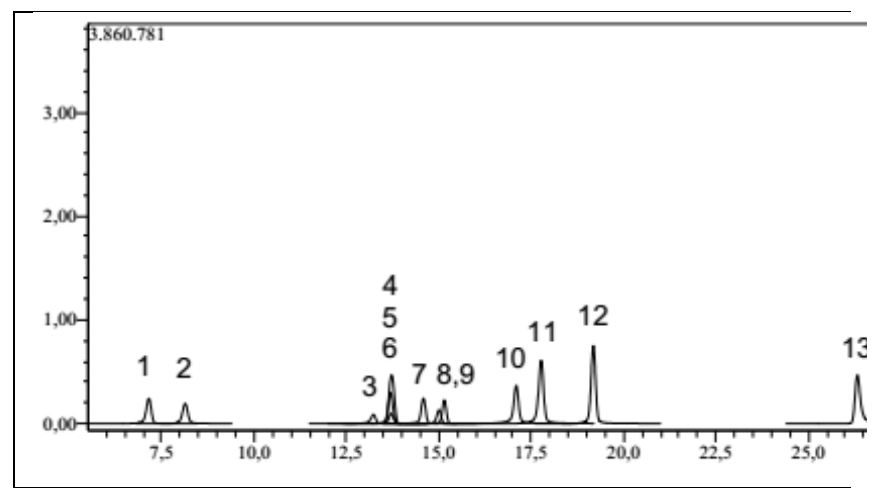

Şekil.1. Fitokimyasal standartın LC-MS/MS kromatogramı (1Hesperidin, 2 Protocatechic acid, 3 Chlorogenic acid, 4 Luteolin-7-glucoside, 5 Hyperoside, 6 Rutin, 7 Apigetrin, 8 
Quercitrine, 9 Astragalin, 10 Quercetin, 11 Luteolin, 12 Apigenin, 13 Hyperforin, 14 Pseudohypericin, 15 Hypericin)

\section{BULGULAR}

$\mathrm{Bu}$ çalışmada, birçok alanda kullanımı olan Origanum cinsinin bir üyesi olan $O$. acutidens'in element analizi, toplam fenolik ve flavonoid analizi, antioksidan aktivite tayini ve fenolik bileşik analizleri yapılmıştır.

O. acutidens'in su ve etanol ekstrelerinin \%DPPH toplam fenolik madde miktarı, toplam flavonoid ve FRAP aktiveteleri ölçülmüş ve elde edilen sonuçlar Tablo 3'te verilmiştir.

Tablo 3. O. acutidens' in su ve etanol ekstrelerinin farklı parametrelere ait analiz sonuçları

\begin{tabular}{|l|c|c|c|c|}
\hline Ekstrakt & $\% \mathrm{DPPH}$ & $\begin{array}{c}\text { Toplam Fenolik } \\
\text { (mg gallik } \\
\text { asit/mL. } \\
\text { ekstrakt) }\end{array}$ & $\begin{array}{c}\text { Toplam } \\
\text { Flavonoid } \\
(\mathrm{mg} \\
\text { rutin/mL. } \\
\left.\text { ekstrakt }^{-1}\right)\end{array}$ & $\begin{array}{c}\text { FRAP } \\
\text { aktivitesi (mg } \\
\text { FeSO } / \mathrm{mL} \\
\text { ekstrakt) }\end{array}$ \\
\hline $\mathrm{Su}$ & $77,53 \pm 4,32-$ & $86,48 \pm 3,68-$ & $280,58 \pm 6,63-$ & $0,34 \pm 0,06-$ \\
\hline Etanol & $90,69 \pm 10,47$ & $142,78 \pm 3,47$ & $503,82 \pm 7,57$ & $0,96 \pm 0,12$ \\
\hline
\end{tabular}

Tablo 3'te görüldüğü gibi, su ve etanol ile elde edilen ekstraktların, toplam fenolik ve flavonoid analizleri sonucunda sirasiyla $86,48 \pm 3,68-142,78 \pm 3,47 \mathrm{mg}$ gallik asit $/ \mathrm{mL}$ ekstrakt, ve $280,58 \pm 6,63-503,82 \pm 7,57 \mathrm{mg}$ rutin $/ \mathrm{mL}$ ekstrakt olarak tespit edilmiştir.

$\mathrm{Bu}$ çalışmada yapılan antioksidan aktivite tayininde \% DPPH ve FRAP yöntemleri kullanılmış ve sonuç olarak su ve etanol ektsraktları için \%DPPH 77,53 \pm 4,32-90,69 \pm 10,47 ve FRAP aktivitesi $0,34 \pm 0,06-0,96 \pm 0,12 \mathrm{mg}$ FeSO $4 / \mathrm{mL}_{\text {ekstrakt }}$ olarak belirlenmiştir (Tablo 3 ).

O. acutidens türünün element miktarlarının belirlenmesi için ICP-MS cihazı kullanılarak analizi yapılmış ve 32 farklı element tespit edilmiştir. Elde edilen sonuçlar Tablo 4'te verilmiştir.

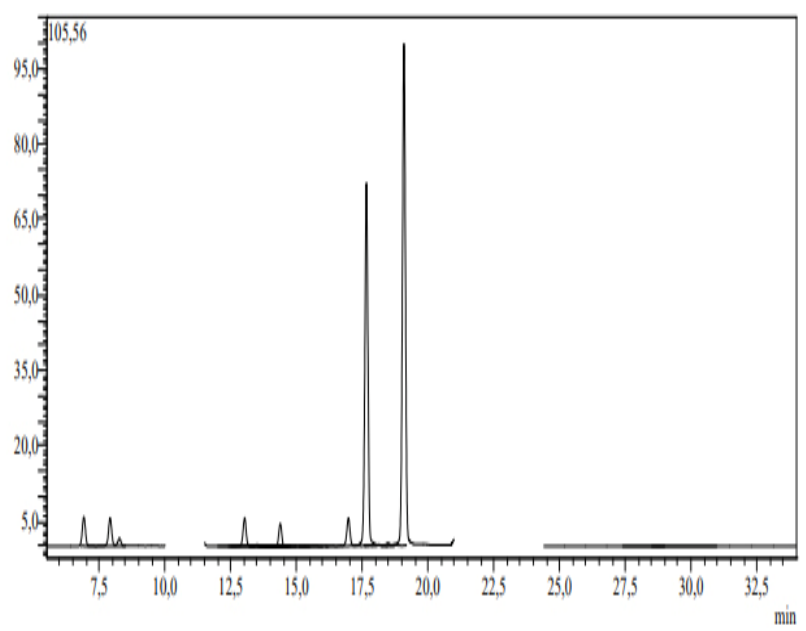

Şekil 2. LC-MS/MS analiz sonucuna ait kromatogram
Tablo 4. $O$. acutidens' in ICP-MS cihazı ile analiz edilmesi sonucu belirlenen elementler

\begin{tabular}{|c|c|}
\hline Element & Değer (ppm) \\
\hline $\mathrm{Li}$ & $0,36 \pm 0,03$ \\
\hline $\mathrm{B}$ & $21,35 \pm 1,69$ \\
\hline $\mathrm{Na}$ & $77,40 \pm 8,02$ \\
\hline $\mathrm{Mg}$ & $1844,41 \pm 0,29$ \\
\hline $\mathrm{Al}$ & $384,93 \pm 0,06$ \\
\hline $\mathrm{P}$ & $1081,52 \pm 0,07$ \\
\hline $\mathrm{K}$ & $19809,98 \pm 3,10$ \\
\hline $\mathrm{Ca}$ & $4243,07 \pm 1,08$ \\
\hline $\mathrm{Cr}$ & $16,75 \pm 1,52$ \\
\hline $\mathrm{Mn}$ & $108,18 \pm 20,53$ \\
\hline $\mathrm{Fe}$ & $3732,56 \pm 694,12$ \\
\hline $\mathrm{Co}$ & $0,76 \pm 0,09$ \\
\hline $\mathrm{Ni}$ & $3,85 \pm 0,22$ \\
\hline $\mathrm{Cu}$ & $10,74 \pm 1,32$ \\
\hline $\mathrm{Zn}$ & $45,87 \pm 5,33$ \\
\hline $\mathrm{Ga}$ & $3,35 \pm 0,23$ \\
\hline As & $0,99 \pm 0,13$ \\
\hline $\mathrm{Se}$ & $90,12 \pm 8,53$ \\
\hline $\mathrm{Sr}$ & $29,29 \pm 7,82$ \\
\hline Mo & $6,25 \pm 0,38$ \\
\hline $\mathrm{Ag}$ & $0,52 \pm 0,03$ \\
\hline $\mathrm{Cd}$ & $1,63 \pm 0,04$ \\
\hline $\mathrm{La}$ & $5,24 \pm 0,71$ \\
\hline $\mathrm{Ce}$ & $6,88 \pm 0,49$ \\
\hline $\mathrm{Pb}$ & $2,07 \pm 0,24$ \\
\hline $\mathrm{Ba}$ & $11,14 \pm 2,52$ \\
\hline Element & Değer (ppb) \\
\hline In & $91,13 \pm 0,06$ \\
\hline $\mathrm{Sn}$ & $251,10 \pm 0,04$ \\
\hline $\mathrm{Sb}$ & $711,29 \pm 0,11$ \\
\hline $\mathrm{Pt}$ & $13,32 \pm 0,01$ \\
\hline $\mathrm{Tl}$ & $27,80 \pm 0,01$ \\
\hline $\mathrm{Bi}$ & $9,50 \pm 0,00$ \\
\hline
\end{tabular}

Fenolik bileşiklerin tespiti için mevcut bulunan ve Tablo 5 'te görülen 15 adet standart kullanılmıştır. Fenolik bileşik analizleri sonucu kullanılan 15 standart bileşikten 7 tanesi bitki örneğinde tespit edilmiştir (Tablo 5; Şekil 2).

Tablo 5. O. acutidens'in kalitatif ve kantitatif fenolik bileşik analiz sonuçları

\begin{tabular}{|l|c|}
\hline Fenolik Bileşik & Değer $(\boldsymbol{\mu g}$ analit/g ekstrakt) \\
\hline Hesperidin & n.d. \\
\hline Protocatechic acid & $15,23 \pm 0,01$ \\
\hline Chlorogenic acid & $17,72 \pm 0,02$ \\
\hline Luteolin-7-glucoside & $33,86 \pm 0,46$ \\
\hline Hyperoside & n.d. \\
\hline Rutin & n.d. \\
\hline Apigetrin & $5,46 \pm 0,00$ \\
\hline Quercitrine & n.d. \\
\hline Astragalin & n.d. \\
\hline Quercetin & $4,56 \pm 0,26$ \\
\hline
\end{tabular}




\begin{tabular}{|l|c|} 
Luteolin & $32,57 \pm 0,01$ \\
\hline Apigenin & $45,08 \pm 0.00$ \\
\hline Hyperforin & n.d. \\
\hline Pseudohypericin & n.d. \\
\hline Hypericin & n.d. \\
\hline n.d.:Tespit edilmedi.
\end{tabular}

\section{DEĞERLENDİRME VE SONUÇ}

Günümüzde temel sağlık hizmeti olarak alternatif tıbbı kullanan insanların sayısı dünya nüfusunun yaklaşık \% 80' nine denk gelmektedir. Bu nedenle alternatif tıpta kullanılan materyallerin farklı parametrelere bağlı yapılan analizleri her geçen gün biraz daha önem taşımaktadır. Yapılan analizlerde elde edilen sonuçlar bize bu bitkisel ürünlerin hangi bileşenlerinin hastalık etmenine etki ettiğini tespit etme firsatı vermektedir. Bitkilerin hastalıklara karşı direnç gösteren bileşikleri böylece belirlenmiş olup onlardan daha fazla faydalanma imkânı sağlanmış olmaktadır. Birçok bitkinin iyileştirici etkisi, içerdiği çok az miktarda eser elementten kaynaklanmaktadır [49]. Mikro besin elementi ya da ağır metallerin konsantrasyonlarının yüksek değerlerde olması ciddi sorunlara neden olmaktadır. $\mathrm{Bu}$ açıdan bitkilerin element içeriklerinin tespiti ile kullanım olanaklarının belirlenmesi konuları önem arz etmektedir [50].

Tablo 4'te göründüğü gibi tespit edilen elementlerden toksik etkiye sahip Arsenik (As), kadmiyum (Cd) ve kurşun (Pb) elementlerinin oranlarının düşük olması ve diğer taraftan demir (Fe), kalsiyum (Ca), poatasyum (K) ve magnezyum $(\mathrm{Mg})$ gibi sağlıklı bir gelişim için gerekli olan elementlerinin oranlarının yüksek olması nedeniyle çalışma materyalini oluşturan $O$. acutidens bitkisinin çay, baharat veya besin maddesi olarak tüketilmesinin insan sağlığına olumlu etkisi olacağı düşünülmektedir.

Oke-Altuntas ve ark. 2018'de yaptıkları çalışmalarında 4 farklı çözücü (su, n-bütanol, etil asetat ve metanol/kloroform $1: 1(\mathrm{v} / \mathrm{v}))$ ile franksiyonlama yaparak $O$. acutidens bitkisinin toprak üstü kısımlarının ekstraktlarında bazı analizleri yapılmıştır. Çalışmanın analiz sonuçlarına göre toplam fenolik madde miktarı 21,34 ile 231,55 $\mu \mathrm{g} / \mathrm{mg}$ aralığında tespit edilmiştir [51]. Bu değerler bu çalışmada elde edilen değerlerle doğru orantılıdır (Tablo 3). Bu durum çalışmanın güvenilirliğini arttırmaktadır. Çalışmamızda bu çalışmadan farklı olarak toplam flavonoid oranı ve bitkide bulunan elementler belirlenmiş ayrıca farklı bir çözücü olarak \%80 etanol kullanılmıştır.

Oke-Altuntas ve ark. 2018'de antioksidan aktivite tayini için DPPH ve metal şelatlama yöntemlerini kullanmışlar ve sonuç olarak DPPH $\left(\mathrm{IC}_{50} \mu \mathrm{g} / \mathrm{mL}\right)$ değerini $11,8->100$ aralığında ve metal şelatlama değerini de $(1 \mathrm{mg} / \mathrm{mL}) \%$ $17,27-78,84$ aralığında tespit etmişler. Çalışmamızda ise yapılan antioksidan aktivite tayininde \%DPPH ve FRAP yöntemleri kullanılmış sonuçları (Tablo 3'te verilmiştir. Ayrıca çalışma sonucunda 7 farklı fenolik bileşik tespit edilmiştir (Tablo 5). Bunlar arasında en fazla bulunan $33,86 \pm 0,46 \mu \mathrm{g}$ analit/g ekstrakt Luteolin-7-glucoside ve en düşük bulunan 4,56 $\pm 0,26 \mu \mathrm{g}$ analit/g ekstrakt Quercetin'dir.

Rump ve ark., (1994) luteolin-7-glukozidin (LUT) fonksiyonel etkileri, sabit basınçta perfüze edilmiş Langendorff-tavşan kalplerinde araştırılmış sonuç olarak; sol ventrikül basıncını ve global ve göreceli koroner akışı (= global koroner akış / basınç oranı ürünü) önemli ölçüde arttırdığı, epikardiyal NADH-floresans alanını ve yoğunluğunu önemli ölçüde azalttığı ve kardiyoprotektif özelliklere sahip bir inodilatör olduğu belirtilmiştir. Bunlar, miyokardiyal perfüzyonun iyileştirilmesi ve / veya serbest radikal süpürücü özelliklerle ilgili olabileceğini açıklamışlar [52]. $\mathrm{Bu}$ sonuçlar $O$. acutidens bitkisinin kalp damar hastalılarının engellenmesinde önemli bir etki yaratabileceğini göstermektedir.

Bitkilerden elde edilen, özellikle fenolik yapıdaki kimyasal maddeler, antioksidan özellikleri sayesinde reaktif oksijen türlerini inaktive ederek oksidatif hasarın önlenmesinde ve giderilmesinde önemli rol oynamaktadırlar [53]. Çalışmamızda gerçekleştirilen analiz sonuçlarına göre elde edilen fenolik bileşikler, bu bileşiklerin toplam oranları, antioksidan aktivite sonuçları ve belirlenen elementlerin oranları göz önünde bulundurulduğunda $O$. acutidens'in çay, baharat veya gida olarak tüketilmesinin sağlığa olumlu etkileri olabileceği belirlenmiştir.

Bitkisel materyaller gelişmiş ve gelişmekte olan ülkelerde ilaç endüstrisi için reçetesiz satılan ilaç ürünleri ve hammaddeler olarak kullanılmaktadır ve küresel ilaç pazarının önemli bir bölümünü temsil etmektedir. Bu nedenle, kalitelerini değerlendirmek için uluslararası kabul görmüş kılavuzların oluşturulması şarttır [54]. Çalışmamız ve benzer çalışma sonuçları bu kılavuzların oluşturulmasında kolaylık sağlayacaktır. Bitkisel formulasyonlarda kullanılan şifalı bitki türlerinin mineral içerikleri, yaşamsal organların düzgün işleyişinde önemli rol oynamanın yanı sıra tahmini güvenli günlük alım miktarının üzerinde toksik olabilmektedir. $\mathrm{Bu}$ açıdan mineral içeriklerinin tespiti ile ilgili bu tarz çalışmalar sıklıkla yapılmalıdır.

\section{REFERANSLAR}

[1]. Linnaeus C. 1754. Genera Plantarum, facsmile edition 1960: 256 Engelmamn (Cramer), Weinheim, Wheldon \& Wesley, Codicote.

[2]. Duman H., Aytaç Z., Ekici M., Karavelioğulları F. A., Dönmez A., Duran A. 1995.Three new species (Labiatae) from Turkey, Flora of Mediterranea, 5, 221-228.

[3]. Ietswaart J.H. 1980. A Taxonomic Revision of the Genus Origanum, Leiden Universty Press, London.

[4]. Güner A.; Aslan S.; Ekim T.; Vural M.; Babaç M. 2012. Türkiye bitkileri listesi (Damarlı bitkiler), Nezahat Gökyiğit Botanik Bahçesi ve Flora Araştırmalar Derneği Yayını: İstanbul. 
[5]. Davis, P.H. (Ed.) 1982. Flora of Turkey and the East Aegean Islands, vol. 7, pp. 297-313, Edinburgh University Press, Edinburgh.

[6].

http://apps.kew.org/wcsp/qsearch.do;jsessionid=E3EF5FAE 37BD73CE5ECFA0B0C4690342

[7]. Doğu S., Dinç M. 2011. Endemik Origanum saccatum P.H. Davis (Lamiaceae) Üzerine Anatomik Bir Çalışma, Ot Sistematik Botanik Dergisi, 18, 2, 45-55.

[8]. Tepe B., Cakir A., \& Sihoglu Tepe A. 2016. Medicinal uses, phytochemistry, and pharmacology of Origanum onites (L.): A Review. Chemistry \& Biodiversity, 13(5), 504-520.

[9]. Walker J. F., Santos P. d. S., Schmidt C. A., Bittencourt T. C. C. d., \& Guimarães A. G. 2016. Antimicrobial Activity of Marjoram (Origanum majorana) Essential Oil Against the Multidrug-Resistant Salmonella Enterica Serovar Schwarzengrund Inoculated in Vegetables from Organic Farming. Journal of Food Safety, 36(4), 489-496.

[10]. Oke Altuntas F., \& Demirtas I. 2017. Real-Time Cell Analysis of the Cytotoxicity of Origanum acutidens Essential Oil on HT-29 and HeLa Cell Lines. Turkish Journal of Pharmaceutical Sciences, 14(1).

[11]. Soliman A. M., Desouky S., Marzouk M., \& Sayed A. A. 2016. Origanum majorana Attenuates Nephrotoxicity of Cisplatin Anticancer Drug through Ameliorating Oxidative Stress. Nutrients, 8(5), 264.

[12]. Yılmaz H., Çarıkçı S., Kılıç T., Dirmenci T., Arabacı T., \& Gören A. C. 2017. Screening of Chemical Composition, Antioxidant and Anticholinesterase Activity of Section Brevifilamentum of Origanum (L.) Species. Department of Biology Educations, Balıkesir.

[13]. Bower A. M., Hernandez L. M. R., Berhow M. A., \& de Mejia E. G. 2014. Bioactive Compounds from Culinary Herbs Inhibit a Molecular Target for Type 2 Diabetes Management, Dipeptidyl Peptidase IV. Journal of Agricultural and Food Chemistry, 62(26), 6147-6158.

[14]. Karaman M., Bogavac M., Radovanović B., Sudji J., Tešanović K., \& Janjušević L. 2017. Origanum vulgare essential oil affects pathogens causing vaginal infections. Journal of applied microbiology, 122(5), 1177-1185.

[15]. Waller S. B., Cleff M. B., Serra E. F., Silva A. L., dos Reis Gomes A., de Mello J. R. B., Meireles M. C. A. 2017. Plants from Lamiaceae family as source of antifungal molecules in humane and veterinary medicine. Microbial Pathogenesis.

[16]. Awaad A. S., El-Meligy R., Qenawy S., Atta A., \& Soliman G. A. 2011. Anti-inflammatory, antinociceptive and antipyretic effects of some desert plants. Journal of Saudi Chemical Society, 15(4), 367-373.

[17]. Quiroga P. R., Grosso N. R., Lante A., Lomolino G., Zygadlo J. A., \& Nepote V. 2013. Chemical composition, antioxidant activity and anti-lipase activity of Origanum vulgare and Lippia turbinata essential oils. International Journal of Food Science and Technology, 48(3), 642-649.

[18]. Özcan M. Mineral contents of someplantsused as condiments in Turkey. Food Chem 2004;84: 437-40.

[19]. Ergün N., Yolcu H., Karanlık S. ve Dikkaya E. 2010. Amanoslarda yetişen bazı bitki türlerinde ağır metal birikimi ve mineral içerik üzerine çalışma. BİBAD;3: 121-7.
[20]. Leblebici S, Bahtiyar SD, Özyurt MS. 2010. Kütahya aktarlarında satılan bazı bitkilerin ağır metal içeriklerinin incelenmesi. DPÜ Fen Bilimleri Enstitüsü Dergisi 2012;29: $1-6$.

[21]. Bedir N. Açık ve Paket Çaylarda Bulunan Ağır Metallerin ICP-OES ile Analizleri. Sakarya Üniversitesi, Fen Bilimleri Enstitüsü Kimya Bilim Dalı, Yüksek Lisans Tezi, Sakarya.

[22]. Öktüren Asri F, Sönmez S, Çıtak S. 2007. Kadmiyumun çevre ve insan sağlığı üzerine etkileri. DERIM 24: 32-9.

[23]. Kahvecioğlu Ö, Kartal G, Güven, Timur S. 2011. Metallerin Çevresel Etkileri - I. http://www.metalurji.org.tr/dergi/ dergi136/d136_4753.pdf [Erişim Tarihi 23.04.]

[24]. Baş L, Demet Ö. Çevresel toksikoloji yönünden bazı ağır metaller. Ekoloji 1992;5: 42-6.

[25]. Topçuoğlu. B. Kentsel katı atık kompostu ve arıtma çamurunda ağır metallerin bitkiler ve çevre üzerinde potansiyel etkileri ve kirletici limitleri. DERİM 2002;19: 38 49 .

[26]. Cragg, G. M., Newman, D. J., \& Snader, K. M. (1997). Natural products in drug discovery and development. Journal of Natural Products, 60(1), 52-60.

[27]. Demirtas, I., Erenler, R., Elmastas, M., \& Goktasoglu, A. (2013). Studies on the antioxidant potential of flavones of Allium vineale isolated from its water-soluble fraction. Food Chemistry, 136(1), 34-40.

[28]. Erenler, R.; Sen, O.; Aksit, H.; Demirtas, I.; Yaglioglu, A.S.; Elmastas, M.; Telci, I. Isolation and identification of chemical constituents from Origanum majorana and investigation of antiproliferative and antioxidant activities. J. Sci. Food Agric., 2016, 96(3), 822-836.

[29]. Topcu, G., Erenler, R., Cakmak, O., Johansson, C. B., Celik, C., Chai, H. B., \& Pezzuto, J. M. (1999). Diterpenes from the berries of Juniperus excelsa. Phytochemistry, 50(7), 1195-1199.

[30]. Baytop T. Türkiye'de Bitkiler İle Tedavi (Geçmişte ve Bugün). Nobel Tıp Kitabevleri, İstanbul. 1999.

[31]. Esen, G., Azaz, A.D., Kurkcuoglu, M., Baser, K.H.C., Tinnaz, A. (2007). Essential oil and antimicrobial activity of wild and cultivated Origanum vulgare L. subsp. hirtum (Link) letswaart from the Marmara region, Turkey. Flavour Fragr., J. 22: 371-376.

[32]. Daouk, R.K., Dagher, S.M., Sattout, E.J. (1995). Antifungal activity of the essential oil of Origanum syriacum L. J. Food Protect. 58: 1147-1149.

[33]. Bouchra, C., Achouri, M., Hassani, L.M.I., Hmamouchi, M. (2003). Chemical composition and antifungal activity of essential oils of seven Moroccan Labiatae against Botrytis cinerea Pers. Fr. J. Ethnopharmacol. 89: 165-169.

[34]. Baydar, H., Sagdic, O., Ozkan, G., Karadogan, T. (2004). Antimicrobial activity and composition of essential oils from Origanum, Thymbra and Satureja species with commercial importance in Turkey. Food Control. 15: 169172.

[35]. Yildirim, E., Kesdek, M., Aslan, I., Calmasur, O., Sahin, F. (2005). The effects of essential oils from eight 
plant species on two pests of stored product insects. Fresen Environ. Bull. 14: 23-27.

[36]. Pichersky, E., Noel, J.P., Dudareva, N. (2006). Biosynthesis of plant volatiles: nature's diversity and ingenuity. Science. 311: 808-811.

[37]. Soylu, S., Yigitbas, H., Soylu, E.M., Kurt, S. (2007). Antifungal effects of essential oils from oregano and fennel on Sclerotinia sclerotiorum. J Appl Microbiol. 103: 10211030 .

[38]. Baser, K.H.C., Tumen, G., Duman, H. (1997). Essential oil of Origanum acutidens (Hund. Murr.) lestwaart. Oil Res. 9: 91-92. 38.

[39]. Kucukgul Gulec A., Erecevit P., Yuce E., Arslan A., Bagci E.\& Kirbag S. 2014. Antimicrobial Activity of the Methanol Extracts and Essential Oil with the Composition of Endemic Origanum acutidens (Lamiaceae). Journal of Essential Oil Bearing Plants, 17:2, 353-358

[40]. Erenler, R.; Meral, B.; Sen, O.; Elmastas, M.; Aydin, A.; Eminagaoglu, O.; Topcu, G. Bioassay-guided isolation, identification of compounds from Origanum rotundifolium and investigation of their antiproliferative and antioxidant activities. Pharm. Biol., 2017, 55(1), 1646-1653.

[41]. Blois, M. S. (1958). Antioxidant determinations by the use of a stable free radical. Nature(26), 1199-1200.

[42]. Müller, S. Gnoyke, A.M. Popken, V. Böhm., 2010. Antioxidant capacity and related parameters of different fruit formulations. LWT Food Sci. Technol., 43 (6) : 992-999.

[43]. Su, L., Yin, J. J., Charles, D., Zhou, K., Moore, J., Yu, L. L., 2007. Total phenolic contents, chelating capacities, and radical-scavening properties of black peppercorn, nutmeg, rosehip, cinnamon and oregano leaf. Food Chemistry, (100): 990-997.

[44]. Park Y-S, Jung S-T, Kang S-G, Heo BK, ArancibiaAvila P, Toledo F, Drzewiecki J, Namiesnik J, Gorinstein S., 2008. Antioxidants and proteins in ethylene-treated kiwifruits. Food Chem. 193-206.

[45]. Teğin İ., Fidan M., Erez M. E. 2018 Siirt-Eruh'ta Doğal Yetişen Tecrium polium L. subsp polium'un Antioksidan Kapasitesi, Toplam Fenolik, Flavonoid İçeriği Ve Element Analizi. Ahtamara 25-26 Ağustos Gevaş Van.
[46].Teğin İ., Fidan M., Erez M. E. 2018 Siirt-Eruh'ta Doğal Yetişen Tecrium polium L. subsp polium'un Antioksidan Kapasitesi, Toplam Fenolik, Flavonoid İçeriği Ve Element Analizi. Ahtamara 25-26 Ağustos Gevaş Van.

[47]. Fidan, M., 2018. Assessment of biological activity and element analysis of Psylliostachys spicata (W1lld.) Nevski. The Journal of Animal and Plant Sciences. 28(6): 16351640 .

[48]. Yılmaz M. A. 2015. Bazı Achıllea L. Türlerinin LCMS-IT/TOF ve LC MS/MS İle Metabolik Profillerinin Çıkarılması Ve Biyolojik Aktivitelerinin Belirlenmesi. Dicle Üniversitesi, Fen Bilimleri Enstitüsü, Kimya Bölümü, Doktora Tezi, Diyarbakır.

[49]. Nema K.N., Maity N., Sarkar K.B., Mukherjee K.P., 2014. Determination of trace and heavy metals in some commonly used medicinal herbs in Ayurveda. Toxicology and Industrial Health, Vol. 30(10) 964-968.

[50]. Yaldız G., Şekeroğlu N. 2013. Tıbbi ve Aromatik Bitkilerin Bazı Ağır Metallere Tepkisi Türk Bilimsel Derlemeler Dergisi 6 (1): 80-84.

[51]. Oke-Altuntas F., Mehmet Ali Demirci M.A., Demirtas I.,*, Ayse Sahin Yaglioglu A. and Behcet L. 2018. Phytochemical Screening, Antiproliferative and Antioxidant Properties of Various Extracts from Endemic Origanum acutidens Combinatorial Chemistry \& High Throughput Screening, 21, 281-291.

[52]. Rump AF, Schussler M, Acar D, Cordes A, Theisohn M, Rosen R, Klaus W, Fricke U. 1994. Functional and antiischemic effects of luteolin-7-glucoside in isolated rabbit hearts. Gen Pharmacol 25:1137-42.

[53]. Çeker S., Orhan F., Medine Güllüce M. ve Ağar G. 2017. Mentha longlfolia L. Hudson ssp. longifolia'dan Elde Edilen Apigenin-7-O- glukozit ve Apigenin-7-O-rutinozit'in Genotoksik Potansiyelleri. MSU Fen Bil. Dergi., Cilt 5, Say1 1, 413-418.

[54]. WHO Quality control methods for medicinal plant materials. WHO Geneva Switzerland. 1998, available at http://whqlibdoc.

who.int/publications/1998/9241545100.pdf. 